\title{
Differences in food habits and cardiovascular disease risk factors among Native Americans with and without diabetes: the Inter-Tribal Heart Project
}

\author{
SL Archer ${ }^{1}$, KJ Greenlund ${ }^{2, *}$, R Valdez $^{3}, \mathrm{ML} \mathrm{Casper}^{2}, \mathrm{~S}$ Rith-Najarian ${ }^{4}$ and JB Croft ${ }^{2}$ \\ 'Department of Preventive Medicine, Northwestern University, Feinberg School of Medicine, Chicago, IL, USA: \\ ${ }^{2}$ Cardiovascular Health Branch, National Center for Chronic Disease Prevention and Health Promotion, Centers for \\ Disease Control and Prevention, 4770 Buford Highway NE, Mailstop K-47, Atlanta, GA 30341-3717, USA: \\ ${ }^{3}$ Division of Diabetes Translation, Atlanta, GA, USA: ${ }^{4}$ Bemidji Area Indian Health Service, Bemidji, MN, USA
}

Submitted 15 January 2004: Accepted 5 May 2004

\begin{abstract}
Objective: To examine differences in food habits among Native Americans with and without diabetes.

Design: A cross-sectional epidemiological study in which participants underwent a physical examination and answered an extensive interviewer-administered questionnaire to assess differences in food servings, preparation and eating habits.

Setting/participants: Participants aged $\geq 25$ years were randomly selected from three reservations in Minnesota and Wisconsin. There were 990 persons without diabetes, 294 with a prior diagnosis of diabetes, and 80 with fasting glucose $>125 \mathrm{mg} \mathrm{dl}^{-1}$ but no prior diabetes diagnosis.

Results: Persons with prior diabetes diagnosis were less likely than those without diabetes to report eating fast-food meals two or more times per week, eat visible fat on meat or the skin on poultry, eat fried chicken or fried fish, to add fat to cooked vegetables and drink whole milk. Persons with previously undiagnosed diabetes were more likely than previously diagnosed persons to report eating fast-food meals two or more times per week, eat visible fat on meat and the skin on poultry, drink whole milk and eat fried fish, but were less likely to drink low-fat milk. Previously undiagnosed persons were more likely than either diagnosed persons or persons without diabetes to consume lard from cooked foods and use it when cooking.

Conclusion: Persons with diagnosed diabetes showed healthier eating patterns than those without diabetes, while undiagnosed persons showed some less favourable patterns. Because virtually all persons with diabetes in these communities receive nutrition education, the results suggest that nutrition education programmes for diabetics may be associated with healthier eating patterns.
\end{abstract}

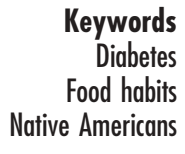

The prevalence of diabetes has increased among Native Americans and Alaska Natives. From 1990 to 1997, diabetes prevalence increased by $30 \%^{1,2}$. Persons with type 2 diabetes are at increased risk of cardiovascular disease $(\mathrm{CVD})^{3,4}$. Heart disease is the leading cause of death among Native Americans ${ }^{5,6}$, and CVD death rates for Native Americans in some regions defined by the Indian Health Service (IHS) are higher than the average CVD death rates for the general US population ${ }^{6}$.

Although nutrition and health education are important in preventing and controlling type 2 diabetes and CVD, results from the Third National Health and Nutrition Examination Survey (NHANES III) indicated that, among US adults with type 2 diabetes, 31\% did not participate in physical activity, $62 \%$ ate fewer than 5 servings of fruits and vegetables per day and almost two-thirds consumed more than $30 \%$ of calories from $\mathrm{fat}^{7}$. Nutrition education among diabetics has been shown to increase participants' knowledge about their diet and improve blood glucose control $^{8,9}$. It has also been reported that communitybased outreach approaches to diabetes management in socially disadvantaged patients improve quality of care dramatically ${ }^{10}$. However, such health education classes are attended only by those persons who have a diabetes diagnosis. There is less information on dietary habits among those with undiagnosed diabetes but with plasma glucose levels that satisfy established criteria for diabetes ${ }^{11}$. From 1992 to 1994, the Centers for Disease Control and Prevention (CDC), the IHS and three Native American communities conducted the Inter-Tribal Heart Project (ITHP) to examine the prevalence of CVD risk factors among community members. In those communities, 
persons diagnosed with diabetes receive standard nutrition education through the IHS and tribal clinics when they are diagnosed. To assess the effectiveness of such nutrition counselling, we examined whether persons with diabetes reported different (and healthier) food habits from persons without diabetes or with undiagnosed diabetes and fasting glucose $\geq 7 \mathrm{mmoll}^{-1}\left(\geq 126 \mathrm{mg} \mathrm{dl}^{-1}\right)$.

\section{Methods}

The ITHP is a CVD epidemiological and health promotion project among adults from one Menominee and two Chippewa communities in Wisconsin and Minnesota ${ }^{12-14}$. Data for the epidemiological study were collected between August 1992 and July 1994. Trained technicians and interviewers gathered information on physiological, medical, psychosocial and behavioural variables. Informed consent was obtained, and the Institutional Review Boards of each participating tribe, the IHS and the CDC approved the study.

Random samples of adults were drawn from IHS clinic user lists for each community, which were determined to be the most reliable sources for identifying members of the resident populations. All persons aged $\geq 25$ years who had used the clinics within the previous 3 years were eligible to participate. A total of 2068 individuals were eligible after excluding deceased, non-resident and institutionalised persons. Among those who were eligible, 19\% declined participation, 14\% agreed to participate but did not report for the examination and $67 \%$ participated in the survey, resulting in a total of 1376 participants ( 527 men and 849 women) $)^{14}$.

Trained interviewers conducted a food habits survey among participants. Food models were used to show portion sizes. Participants recalled how many times a week they consumed certain foods; for example, 'How many 3-Oz portions of chicken or turkey do you eat per week?' Participants reported the number of food servings eaten daily, weekly or monthly, and these were standardised to the number of servings eaten per week for these analyses. Other questions ascertained food preparation and eating habits, including frequency of eating at fast-food restaurants, whether particular foods eaten were usually fried, types of fat used in cooking and added to cooked foods, and other food preparation methods. Due to length and time constraints, the tool used to assess dietary intake was adapted from standard food frequency surveys available at the time the study was developed and basically assessed frequency of intake. The selection of foods to be included was based on extensive collaborations between the IHS, CDC and the tribes that participated. Local representatives (tribal members) helped to determine the food topics based on foods eaten in the area and methods of preparation.

Nutrition education is provided to those with diabetes. For persons with diabetes, the IHS and tribal clinic nutrition education programme serving ITHP communities consisted of an annual consultation with a registered dietitian, who conducted a standardised IHS assessment of the patient's food habits and negotiated a food plan centred on the principles of 'eat less sugar, eat less fat, eat more fibre, and eat less food'. The IHS diabetes programme conducted annual standardised medical record audits of diabetes care, and in 1992, 62\% ( $n$ audited $=183$ ) of patients with diagnosed diabetes in the ITHP communities had documentation of nutritional education $^{15}$.

Participants were instructed to fast for at least $12 \mathrm{~h}$ prior to their physical examination. Blood chemistry was measured at the Medical Research Laboratory (Highland Heights, KY, USA). Serum total cholesterol, triglycerides, high-density lipoprotein cholesterol (HDL-C) and glucose were determined by enzymatic methods using a Hitachi 737 chemistry analyser and reagents from Boehringer Mannheim Diagnostics (Indianapolis, IN, USA). Lowdensity lipoprotein cholesterol (LDL-C) was calculated using the Friedewald formula ${ }^{16}$ and was not calculated if triglycerides were $>4.52 \mathrm{mmol}^{-1}\left(400 \mathrm{mg} \mathrm{dl}^{-1}\right)$. Dyslipidaemia was categorised as follows: total cholesterol, $\geq 6.21 \mathrm{mmol} \mathrm{l}^{-1}\left(240 \mathrm{mg} \mathrm{dl}^{-1}\right) ;$ LDL-C,$\geq 4.14 \mathrm{mmoll}^{-1}$ $\left(160 \mathrm{mg} \mathrm{dl}^{-1}\right)$; HDL-C, $<0.91 \mathrm{mmoll}^{-1}\left(35 \mathrm{mg} \mathrm{dl}^{-1}\right)^{16}$. High triglycerides was defined as a value $\geq 2.82 \mathrm{mmoll}^{-1}\left(250 \mathrm{mg} \mathrm{dl}^{-1}\right)^{17}$. These cut-off points were those recommended by expert panels at the time of the study.

Physical examinations were conducted in tribal clinics by trained technicians. Blood pressure was measured with a mercury sphygmomanometer three times after an initial 5-min rest; the average of the second and third readings was used to estimate systolic (first Korotkoff sound) and diastolic (fifth Korotkoff sound) blood pressure. Hypertension was defined as systolic pressure $\geq 140 \mathrm{mmHg}$ or diastolic pressure $\geq 90 \mathrm{mmHg}$ or current use of hypertension medication ${ }^{18}$. Height $(\mathrm{cm})$ and weight $(\mathrm{kg})$ were measured with the patient dressed in light clothing and without shoes. Obesity was defined ${ }^{19}$ as body mass index (BMI) $\geq 30.0 \mathrm{~kg} \mathrm{~m}^{-2}$. Current cigarette smoking status and sedentary leisure-time activity were determined by a questionnaire administered by trained interviewers. Sedentary leisure time was defined as no participation in sports, exercise, gardening or other leisure-time activity during the previous 12 months. Known diabetes status was based on the person having been told by a doctor they had diabetes or current taking of diabetes medications. Previously undiagnosed diabetes status was based on the participant having a fasting glucose level $\geq 7 \mathrm{mmoll}^{-1}$ $\left(\geq 126 \mathrm{mg} \mathrm{dl}^{-1}\right.$ ) but reporting they had not been told they had diabetes or not taking diabetes medications.

Analyses included data for 1364 participants whose diabetes status was known. We examined differences in food servings, food habits and risk factor levels by diabetes status. Differences between groups were 
assessed by analysis of variance for continuous variables and by chi-square tests for categorical variables. Analysis of covariance for continuous dependent variables and multivariable logistic regression for categorical dependent variables were carried out for analyses adjusting for age and gender. Two sets of multivariable logistic models were used. To compare persons with diabetes with those without diabetes, the first model included dummy variables for prior and previously undiagnosed diabetes along with age and gender, with non-diabetic persons as the referent group. To compare previously undiagnosed persons with prior diagnosed persons, the second model included dummy variables for normal glucose and newly diagnosed persons along with age and gender, with previously diagnosed persons as the referent. A significance level of $P \leq 0.05$ for two-tailed tests was used to determine statistical significance.

\section{Results}

Of the 1364 participants, 990 persons did not have diabetes, 294 persons had a prior diabetes diagnosis and 80 persons had undiagnosed diabetes (Table 1). Compared with other groups, a higher percentage of persons with previously undiagnosed diabetes were men $(47.5 \%$, vs. $35.7 \%$ of previously diagnosed persons and $37.1 \%$ of persons without diabetes). There was a greater percentage of persons aged $\geq 65$ years among those with a prior diabetes diagnosis (28.6\%) than among those who were previously undiagnosed $(13.7 \%)$ or who did not have diabetes (9.2\%).

Overall, almost $36 \%$ of persons had at least one dyslipidaemia, 32\% had high blood pressure and $47 \%$ were considered obese. Sixty per cent of persons with high blood pressure were taking hypertension medication, and $52 \%$ of persons with a prior diabetes diagnosis were taking diabetes medications. Persons with either previously diagnosed or previously undiagnosed diabetes were more likely to have high total cholesterol, high triglycerides, low HDL-C or any dyslipidaemia, compared with persons without diabetes. Persons with either previously diagnosed or previously undiagnosed diabetes were more likely to have hypertension and BMI $\geq 30 \mathrm{~kg} \mathrm{~m}^{-2}$ than were persons without diabetes.

Compared with persons without diabetes, age- and gender-adjusted analyses suggested that persons with prior diabetes diagnosis reported eating fewer servings of beef or pork and desserts per week, and slightly more servings of oatmeal or oat foods and servings of fruit per week (Table 2). Other food servings showed somewhat favourable trends but were not statistically significant. Persons with previously undiagnosed diabetes reported more servings of fruit or vegetable juice than did persons without diabetes; no other differences were statistically significant.

Food habits by diabetes status are shown in Table 3. In multivariable analyses adjusting for age and gender,

Table 1 Characteristics of participants $(n=1364)$ by diabetes status, Inter-Tribal Heart Project

\begin{tabular}{|c|c|c|c|c|c|c|c|c|}
\hline \multirow[b]{2}{*}{ Characteristic } & \multicolumn{2}{|c|}{ Total $(n=1364)$} & \multicolumn{2}{|c|}{$\begin{array}{l}\text { Persons without } \\
\text { diabetes }(n=990)\end{array}$} & \multicolumn{2}{|c|}{$\begin{array}{l}\text { Persons with prior } \\
\text { diabetes diagnosis } \\
\qquad(n=294)\end{array}$} & \multicolumn{2}{|c|}{$\begin{array}{l}\text { Persons with } \\
\text { undiagnosed } \\
\text { diabetes } \\
(n=80)\end{array}$} \\
\hline & $n / N$ & $\%$ & $n / N$ & $\%$ & $n / N$ & $\%$ & $n / N$ & $\%$ \\
\hline \multicolumn{9}{|l|}{ Gender } \\
\hline Female & $854 / 1364$ & 62.6 & $623 / 990$ & 62.9 & $189 / 294$ & 64.3 & $42 / 80$ & 52.5 \\
\hline Male & $510 / 1364$ & 37.4 & $367 / 990$ & 37.1 & $105 / 294$ & 35.7 & $38 / 80$ & 47.5 \\
\hline \multicolumn{9}{|l|}{ Age group (years) } \\
\hline $25-44$ & $598 / 1363$ & 43.9 & $534 / 989$ & 54.0 & $38 / 294$ & 12.9 & $26 / 80$ & 32.5 \\
\hline $45-64$ & $579 / 1363$ & 42.5 & $364 / 989$ & 36.8 & $172 / 294$ & 58.5 & $43 / 80$ & 53.7 \\
\hline 65 and older & $186 / 1363$ & 13.6 & 91/989 & 9.2 & $84 / 294$ & 28.6 & $11 / 80$ & 13.7 \\
\hline \multicolumn{9}{|l|}{ Education } \\
\hline Less than high school & $405 / 1348$ & 30.0 & 260/985 & 26.4 & $120 / 283$ & 42.4 & $25 / 80$ & 31.2 \\
\hline High school & $437 / 1348$ & 32.4 & $320 / 985$ & 32.5 & $84 / 283$ & 29.7 & $33 / 80$ & 41.2 \\
\hline More than high school & $506 / 1348$ & 37.5 & $405 / 985$ & 41.1 & $79 / 283$ & 27.9 & $22 / 80$ & 27.5 \\
\hline \multicolumn{9}{|l|}{ Dyslipidaemias } \\
\hline Total cholesterol $\geq 6.21 \mathrm{mmoll}^{-1}$ & 295/1359 & 21.7 & 196/988 & 19.8 & $79 / 291$ & 27.1 & $20 / 80$ & 25.0 \\
\hline Triglycerides $\geq 2.82 \mathrm{mmoll}^{-1}$ & 206/1359 & 15.2 & 98/988 & 9.9 & $82 / 291$ & 28.2 & $26 / 80$ & 32.5 \\
\hline LDL-C $\geq 4.14 \mathrm{mmolI}^{-1}$ & 232/1307 & 17.7 & $164 / 970$ & 16.9 & $55 / 264$ & 20.8 & $13 / 73$ & 17.8 \\
\hline $\mathrm{HDL}-\mathrm{C}<0.91 \mathrm{mmoll}^{-1}$ & $130 / 1358$ & 9.6 & $77 / 988$ & 7.8 & $39 / 291$ & 13.4 & $14 / 80$ & 17.5 \\
\hline Any dyslipidaemia & $485 / 1359$ & 35.7 & $309 / 988$ & 31.3 & $135 / 291$ & 46.4 & $41 / 80$ & 51.2 \\
\hline Hypertension & $435 / 1364$ & 31.9 & $237 / 990$ & 23.9 & $167 / 294$ & 56.8 & $31 / 80$ & 38.7 \\
\hline $\mathrm{BMI} \geq 30.0 \mathrm{~kg} \mathrm{~m}^{-2}$ & $634 / 1352$ & 46.9 & $407 / 980$ & 41.5 & $175 / 293$ & 59.7 & $52 / 79$ & 65.8 \\
\hline \multicolumn{9}{|l|}{ Smoking status } \\
\hline Never & $199 / 1353$ & 14.7 & $139 / 985$ & 14.1 & $47 / 288$ & 16.3 & $13 / 80$ & 16.2 \\
\hline Former & $413 / 1353$ & 30.5 & $274 / 985$ & 27.8 & $117 / 288$ & 40.6 & $22 / 80$ & 27.5 \\
\hline Current & $741 / 1353$ & 54.8 & $572 / 985$ & 58.1 & $124 / 288$ & 43.1 & $45 / 80$ & 56.2 \\
\hline No leisure-time physical activity & $378 / 1344$ & 28.1 & 252/983 & 25.6 & 99/281 & 35.2 & $27 / 80$ & 33.7 \\
\hline
\end{tabular}

LDL-C - low-density lipoprotein cholesterol; HDL-C - high-density lipoprotein cholesterol; BMI - body mass index.

Hypertension status: systolic blood pressure $\geq 140 \mathrm{mmHg}$, diastolic blood pressure $\geq 90 \mathrm{mmHg}$ or taking hypertension medication. 
Table 2 Reported food servings per week by diabetes status, Inter-Tribal Heart Project

\begin{tabular}{|c|c|c|c|}
\hline \multirow[b]{2}{*}{ Food } & \multicolumn{3}{|c|}{ Servings per week, mean (standard error) } \\
\hline & $\begin{array}{l}\text { Persons without } \\
\text { diabetes }\end{array}$ & $\begin{array}{l}\text { Persons with } \\
\text { prior diabetes diagnosis }\end{array}$ & $\begin{array}{c}\text { Persons with } \\
\text { undiagnosed diabetes }\end{array}$ \\
\hline 3-oz portions of beef or pork & $6.2(0.16)^{\mathrm{a}}$ & $5.4(0.31)^{\mathrm{a}}$ & $5.9(0.55)$ \\
\hline 3-oz portions of chicken or turkey & $2.1(0.07)$ & $2.0(0.13)$ & $1.8(0.23)$ \\
\hline Servings of fish (3 oz per serving) & $0.9(0.03)$ & $1.0(0.06)$ & $0.9(0.11)$ \\
\hline Servings of oatmeal or oat foods & $2.3(0.09)^{\mathrm{c}}$ & $3.0(0.18)^{\mathrm{C}}$ & $2.4(0.32)$ \\
\hline $1 / 2$-cup servings of dried beans & $1.1(0.05)$ & $1.0(0.09)$ & $1.1(0.16)$ \\
\hline 1-oz servings of cheese & $3.8(0.17)$ & $3.5(0.34)$ & $4.0(0.60)$ \\
\hline Number of eggs & $4.9(0.18)$ & $5.0(0.36)$ & $5.6(0.63)$ \\
\hline $1 / 2$-cup servings of rice, pasta, potatoes, cereal & $1.7(0.11)$ & $1.7(0.22)$ & $1.4(0.39)$ \\
\hline Bread, 1 slice & $20.4(0.46)$ & $22.2(0.89)$ & $22.0(1.6)$ \\
\hline Bowls of salads (green or vegetable) & $2.7(0.12)$ & $2.7(0.22)$ & $2.7(0.40)$ \\
\hline $1 / 2$-cup servings of vegetables & $7.6(0.17)$ & $8.0(0.32)$ & $7.4(0.57)$ \\
\hline 1/2-cup servings of fruit or vegetable juice & $6.5(0.28)^{b}$ & $7.1(0.53)$ & $9.1(0.96)^{b}$ \\
\hline Servings of fruit & $5.6(0.19)^{b}$ & $6.6(0.36)^{b}$ & $5.8(0.64)$ \\
\hline 1-cup servings of milk & $7.3(0.28)$ & $8.3(0.55)$ & $6.2(0.97)$ \\
\hline Desserts & $4.1(0.17)^{\mathrm{C}}$ & $2.8(0.33)^{\mathrm{C}}$ & $3.3(0.59)$ \\
\hline Salty snacks & $3.9(0.18)$ & $3.8(0.34)$ & $4.7(0.62)$ \\
\hline 1-tsp servings butter, margarine, real mayonnaise & $18.1(0.50)$ & $18.4(0.97)$ & $18.2(1.7)$ \\
\hline
\end{tabular}

Means are adjusted for age and gender.

a'Difference between diabetes status groups with similar superscript is statistically significant, $P \leq 0.05$.

${ }^{b}$ Difference between diabetes status groups with similar superscript is statistically significant, $P \leq 0.01$.

${ }^{\mathrm{C}}$ Difference between diabetes status groups with similar superscript is statistically significant, $P \leq 0.005$.

persons with prior diabetes diagnosis were less likely than persons without diabetes to report eating fast-food meals two or more times per week, less likely to eat visible fat on meat or the skin on poultry, somewhat more likely to drink low-fat milk and less likely to drink whole milk, less likely to eat fried chicken or fried fish, and less likely to add fat to cooked vegetables.

In analyses adjusting for age and gender, persons with previously undiagnosed diabetes were more likely than persons with prior diabetes diagnosis to report eating fastfood meals two or more times per week, more likely to eat the visible fat on meat and the skin on poultry, less likely to drink low-fat milk and more likely to drink whole milk, and more likely to always eat fried fish. Persons with previously undiagnosed diabetes were more likely than either persons with previously diagnosed diabetes or persons without diabetes to use lard or meat drippings in cooked foods and when cooking.

\section{Discussion}

Guidelines for primary and secondary prevention of diabetes and CVD include dietary counselling ${ }^{20-22}$. In this context, findings from the Inter-Tribal Heart Project provide interesting insights into the association between health education and dietary habits among a population at high risk for diabetes and CVD.

In the USA, only about $19 \%$ of physician office visits for routine examination include counselling for physical activity, 2.8\% include diet counselling and 10.4\% include weight reduction advice ${ }^{23}$. Diabetes self-management is most effective when behavioural change strategies are incorporated into the education process ${ }^{24}$. A meta-analysis of various intervention methods among persons with diabetes suggested that dietary instruction has a significant effect on knowledge gain ${ }^{25}$. However, the Healthy Eating Index reported that only 10\% of American Indians have healthy diets ${ }^{26}$ and many health-care professionals do not pursue diet counselling with Native American patients ${ }^{27,28}$. Diet and exercise that induce a $5-7 \%$ weight loss can reduce the incidence of diabetes by $58 \%$ in high-risk individuals ${ }^{29}$. Similar results were reported from a Finnish study on diet and exercise intervention for those with impaired glucose tolerance (IGT). A 58\% relative reduction in diabetes incidence was reported for the intervention group $^{30}$. In the Da Qing IGT and Diabetes Study, 577 participants with IGT received diet and exercise intervention. The diet, exercise and diet-plus-exercise interventions were associated with $31 \%, 46 \%$ and $42 \%$ reductions in the risk of developing diabetes, respectively ${ }^{31}$.

Although the cross-sectional nature and small sample size of our study does not allow us to presume cause and effect, the observation that persons with previously undiagnosed diabetes (based on fasting glucose level) reported some worse food habits than those with diabetes might result from the education that diabetic persons receive through diabetes care. More longitudinal observations are needed to confirm this. In the ITHP, a large percentage of persons who had diabetes reported that they received nutrition and diet counselling at the IHS and/or tribal clinics.

Clinics serving these communities also provide community-based health education programmes that are available to all community members. Although 29\% of participants reported they were aware of programs to reduce CVD risk, only $2-11 \%$ participated in any such 
Table 3 Reported food habits by diabetes status, Inter-Tribal Heart Project

\begin{tabular}{|c|c|c|c|c|c|c|}
\hline \multirow[b]{2}{*}{ Food habits reported } & \multicolumn{2}{|c|}{$\begin{array}{l}\text { Persons without } \\
\text { diabetes }\end{array}$} & \multicolumn{2}{|c|}{$\begin{array}{l}\text { Persons with } \\
\text { prior diabetes } \\
\text { diagnosis }\end{array}$} & \multicolumn{2}{|c|}{$\begin{array}{l}\text { Persons with } \\
\text { undiagnosed } \\
\text { diabetes }\end{array}$} \\
\hline & $n / N$ & $\%$ & $n / N$ & $\%$ & $n / N$ & $\%$ \\
\hline \multicolumn{7}{|l|}{ How often eat fast-food meals? } \\
\hline Never & $126 / 985$ & 12.8 & $56 / 278$ & 20.1 & $13 / 78$ & 16.7 \\
\hline Less than once per week & 285/985 & 28.9 & $91 / 278$ & 32.7 & $18 / 78$ & 23.1 \\
\hline Once per week & 291/985 & 29.5 & 79/278 & 28.4 & $17 / 78$ & 21.8 \\
\hline Two or more times per week & $283 / 985$ & $28.7^{\mathrm{a}}$ & $52 / 278$ & $18.7^{\mathrm{b}}$ & $30 / 78$ & $38.5^{\text {a.b }}$ \\
\hline Usually eats the visible fat on meat & $315 / 981$ & 32.1 & $82 / 273$ & $30.0^{\mathrm{C}}$ & $33 / 77$ & $42.9^{\mathrm{C}}$ \\
\hline Does not eat meat & 10/981 & 1.0 & $1 / 273$ & 0.4 & $1 / 77$ & 1.3 \\
\hline Usually eats the skin on chicken and turkey & $558 / 979$ & $57.0^{\mathrm{C}}$ & $122 / 273$ & $44.7^{\mathrm{c}, \mathrm{d}}$ & $47 / 77$ & $61.0^{\mathrm{d}}$ \\
\hline Does not eat chicken or turkey & 28/979 & 2.9 & $8 / 273$ & 2.9 & $3 / 77$ & 3.9 \\
\hline \multicolumn{7}{|l|}{$\begin{array}{l}\text { Of cheese you eat, how often is it low-fat, } \\
\text { reduced-calorie or lite? }\end{array}$} \\
\hline Almost always & $116 / 957$ & 12.1 & $45 / 268$ & 16.8 & $12 / 71$ & 16.9 \\
\hline Half the time/sometimes & $137 / 957$ & 14.3 & $27 / 268$ & 10.1 & $3 / 71$ & 4.2 \\
\hline Rarely or never & $625 / 957$ & 65.3 & $164 / 268$ & 61.2 & $49 / 71$ & 69.0 \\
\hline Does not eat cheese & 79/957 & 8.2 & $32 / 268$ & 11.9 & 7/71 & 9.9 \\
\hline \multicolumn{7}{|l|}{ Type of milk usually drunk } \\
\hline Skimmed or low-fat $1 \%$ & $120 / 980$ & $12.2^{\mathrm{e}}$ & $36 / 274$ & $13.1^{\mathrm{e}, \mathrm{a}}$ & $3 / 76$ & $3.9^{\mathrm{a}}$ \\
\hline Low-fat $2 \%$ & $450 / 980$ & 45.9 & $162 / 274$ & 59.1 & $36 / 76$ & 47.4 \\
\hline Whole & $131 / 980$ & $13.4^{\mathrm{e}}$ & $16 / 274$ & $5.8^{e, f}$ & $12 / 76$ & $15.8^{f}$ \\
\hline Does not drink milk & 279/980 & 28.5 & $60 / 274$ & 21.9 & $25 / 76$ & 32.9 \\
\hline \multicolumn{7}{|l|}{ Type of butter or margarine usually used } \\
\hline Butter & 285/973 & 29.3 & $66 / 272$ & $24.3^{\mathrm{a}}$ & $28 / 74$ & $37.8^{\mathrm{a}}$ \\
\hline Tub margarine/squeeze margarine & $231 / 973$ & 23.7 & $79 / 272$ & 29.0 & $11 / 74$ & 14.9 \\
\hline Stick margarine & $447 / 973$ & 45.9 & $126 / 272$ & 46.3 & $33 / 74$ & 44.6 \\
\hline Does not use butter or margarine & $10 / 973$ & 1.0 & $1 / 272$ & 0.4 & 2/74 & 2.7 \\
\hline \multicolumn{7}{|l|}{ Of the beef/pork you eat, how often is it fried? } \\
\hline Almost always & $287 / 980$ & 29.3 & $57 / 274$ & 20.8 & $25 / 75$ & 33.3 \\
\hline Half the time/sometimes & $500 / 980$ & 51.0 & $138 / 274$ & 50.4 & $37 / 75$ & 49.3 \\
\hline Rarely or never & $178 / 980$ & 18.2 & $78 / 274$ & 28.5 & $12 / 75$ & 16.0 \\
\hline Does not eat beef or pork & $15 / 980$ & 1.5 & $1 / 274$ & 0.4 & $1 / 75$ & 1.3 \\
\hline \multicolumn{7}{|l|}{ Of the chicken you eat, how often is it fried? } \\
\hline Almost always & $197 / 979$ & 20.1 & $44 / 273$ & 16.1 & $16 / 74$ & 21.6 \\
\hline Half the time/sometimes & $382 / 979$ & 39.0 & $88 / 273$ & 32.2 & $25 / 74$ & 33.8 \\
\hline Rarely or never & $367 / 979$ & $37.5^{\mathrm{e}}$ & $133 / 273$ & $48.7^{\mathrm{e}}$ & $30 / 74$ & 40.5 \\
\hline Does not eat chicken & $33 / 979$ & 3.4 & $8 / 273$ & 2.9 & $3 / 74$ & 4.0 \\
\hline \multicolumn{7}{|l|}{ Of the fish you eat, how often is it fried? } \\
\hline Almost always & $452 / 983$ & $46.0^{\mathrm{a}}$ & $107 / 274$ & $39.0^{\mathrm{a}, \mathrm{b}}$ & $36 / 75$ & $48.0^{\mathrm{b}}$ \\
\hline Half the time/sometimes & $217 / 983$ & 22.1 & $59 / 274$ & 21.5 & $13 / 75$ & 17.3 \\
\hline Rarely or never & $173 / 983$ & $17.6^{\mathrm{a}}$ & $78 / 274$ & $28.5^{\mathrm{a}}$ & $11 / 75$ & 14.7 \\
\hline Does not eat fish & $141 / 983$ & 14.3 & $30 / 274$ & 10.9 & $15 / 75$ & 20.0 \\
\hline \multicolumn{7}{|l|}{ Kind of fat usually added to cooked vegetables } \\
\hline Liquid cooking oils & $84 / 963$ & 8.7 & $23 / 268$ & 8.6 & $4 / 74$ & 5.4 \\
\hline Margarine or solid vegetable shortening & $305 / 963$ & 31.7 & $76 / 268$ & 28.4 & $12 / 74$ & 16.2 \\
\hline Lard, meat drippings or butter & $221 / 963$ & $22.9^{\mathrm{a}}$ & $51 / 268$ & $19.0^{\mathrm{b}}$ & $24 / 74$ & $32.4^{\mathrm{a}, \mathrm{b}}$ \\
\hline Does not add fat to cooked vegetables & $353 / 963$ & $36.7^{\mathrm{c}}$ & $118 / 268$ & $23.4^{\mathrm{C}}$ & $34 / 74$ & 45.9 \\
\hline Skims the fat from meat juices & $664 / 951$ & 69.8 & $205 / 268$ & 76.5 & $49 / 74$ & 66.2 \\
\hline Usually adds salt to foods at the table & $754 / 978$ & 77.1 & $190 / 272$ & 69.8 & $64 / 78$ & 82.0 \\
\hline
\end{tabular}

${ }^{a, b}$ Difference between diabetes status groups with similar superscript is statistically significant, $P \leq 0.01$.

${ }^{\mathrm{c}, \mathrm{d}}$ Difference between diabetes status groups with similar superscript is statistically significant, $P \leq 0.05$.

${ }^{\mathrm{e}, \mathrm{f}}$ Difference between diabetes status groups with similar superscript is statistically significant, $P \leq 0.005$.

programmes. For the programmes specifically on diet and heart disease, less than $10 \%$ of men and women in the ITHP reported any participation ${ }^{14}$. The health education classes offered to those diagnosed with diabetes is standard care practice, which is more than persons in the general community receive. Therefore, it might be expected that persons with diabetes have better eating habits as a result of diabetes education.

We recently reported that, among persons with diabetes, there were no differences in reported food habits between those who attended and those who did not attend such community-based health education programmes $^{32}$. Although no differences were observed, such programmes may reinforce healthy behaviours learned in the clinic setting. Furthermore, for persons without diabetes or other chronic disease who may not receive specialised counselling, such community-based programmes may be the only local sources of health information. There is a paucity of data available on dietary habits among Native Americans with diagnosed and 
undiagnosed diabetes. Results from the ITHP study shed light on a lifestyle factor among a population that is at high risk for chronic disease.

Food preparation methods are also associated with poor glycaemic control and increased risk for diabetes. In our study, some reported preparation methods used by diabetics appeared to be healthier than those used by persons without diabetes. Persons with diabetes were more likely not to fry chicken or fish than were persons without diabetes, and not to add fat to cooked vegetables. Gittelsohn et al. reported that, among native Canadians who resided on reserves in north-western Ontario province, choice of cooking method and addition of fat during preparation increased the risk of IGT two-fold ${ }^{33}$. In the present study, those who were told they had diabetes had more favourable dietary habits than those with high fasting glucose, and showed some healthier patterns than persons without diabetes. This observation supports the probability that those diagnosed with diabetes changed dietary habits after being diagnosed. Various programmes are implemented by the IHS for individuals with diagnosed diabetes; however, to reduce the risk of developing diabetes, it would be useful to expand these programmes to include those who may have risk factors that predispose them to diabetes, such as IGT or high glucose levels ${ }^{34}$.

The cross-sectional nature of the study limits our knowledge about the duration of dietary patterns and whether differences in food habits are related to nutrition counselling. However, nutrition education efforts that teach specific behavioural skills can influence eating habits $^{27}$. The ITHP study used a dietary tool that was interviewer-administered; therefore, even though $42 \%$ of people with diabetes had less than a high school education, participant education level would not affect use of the tool. The small sample sizes in our study also limit our ability to adjust for various factors that may be related to differences in food habits. For example, comorbid conditions may influence eating habits, but it is not known whether differences are due to diabetes status or to other factors such as co-morbidities with diabetes. Because this is a cross-sectional study, we are unable to determine improvements in some metabolic outcomes. Although people with diabetes in our study may have improved blood glucose and lipid levels, these improvements may not be observed when compared with the levels of non-diabetics. Miller et al. reported similar results in a 10-week nutrition intervention study that evaluated the intervention impact on blood glucose and lipid levels among people with diabetes ${ }^{35}$. Despite improvements in blood glucose levels, less than half of the participants met guidelines for metabolic outcomes set by the American Diabetes Association ${ }^{35}$. Many diabetes education programmes have been criticised as being too brief to meet the needs of clients ${ }^{34}$. It is also possible that greater improvements in metabolic parameters require more intensive therapy that combines exercise, diet and pharmacological therapy ${ }^{35}$. Moreover, the extent to which persons may be able to change their diets may be influenced by environmental and economic development factors that include food availability and $\operatorname{cost}^{36-38}$.

In addition to the limits of a cross-sectional study design, there may be misreporting of dietary intake, which could lead to a measurement error especially since some participants had received some nutrition education and others had not ${ }^{39-41}$. There are various factors related to misreporting in dietary data collection, including misinterpretation of portion sizes, psychosocial factors related to health such as the stigmatism of obesity and demographic factors such as socio-economic status ${ }^{42}$. Another factor that may lead to misreporting is exposure to nutrition education or public health messages. In the ITHP study the diabetic participants were offered nutrition education and this could subsequently lead to dietary recall bias. Nutrition education programmes at the work-site have shown to influence dietary changes such as a reduction in dietary fat intake ${ }^{43}$. Peer support can lead to increased intakes of nutrients such as calcium among preadolescent females ${ }^{44}$. Therefore nutrition education can result in actual changes in dietary behaviours.

Currently, federally funded research emphasises participatory approaches in community health studies ${ }^{45}$. It is possible that self-directed learning experiences that are based on an appreciation for the culture and history of a group may be more effective. A randomised lifestyle intervention conducted among Pima Indians in Arizona reported that the group which was allowed to have experiences in their intervention that were self-directed, based on their culture and history, maintained their better lifestyle habits for longer than the group provided with structured lifestyle intervention guidelines ${ }^{46}$. Early prevention can also be effective. The IHS is now placing special emphasis on prevention of diabetes by the efforts of paediatricians involved in the care of children living on reservations ${ }^{47}$.

The dietary habits survey utilised in the ITHP study was developed by the CDC and IHS based on standard food frequency surveys available at the time, such as NHANES. The survey developed was a shorter and simple measurement tool of food habits, which could provide relevant information for planning health promotion efforts in the ITHP communities ${ }^{14}$.

Dietary intervention, along with other lifestyle interventions, should be the first approach in primary prevention and an important component of secondary diabetes prevention. The serious consequences of diabetes and CVD in the Native American population suggest that efforts to reduce the burden of these diseases need to be intensified. 


\section{Acknowledgements}

The people who agreed to participate in the Inter-Tribal Heart Project and the local tribal governments made this work possible. The project was supported by a Memorandum of Understanding between the Centers for Disease Control and Prevention and the Indian Health Service, and by the following Tribal Council Resolutions: 9142 of the Menominee Tribe of Wisconsin, 15791 of the Red Lake Band of Chippewa Indians and 06392001 of the White Earth Reservation Tribal Council.

\section{References}

1 Burrows NR, Geiss LS, Engelgau MM, Acton KJ. Prevalence of diabetes among Native Americans and Alaska Natives, 1990-1997. Diabetes Care 2000; 23: 1786-90.

2 Howard BV, Lee ET, Cowan LD, Devereaux RB, Galloway $\mathrm{JM}$, Go OT, et al. Rising tide of cardiovascular disease in American Indians. The Strong Heart Study. Circulation 1999; 99: 2389-95.

3 Dabelea D, Hanson RL, Bennett PH, Roumain J, Knowler WC, Pettitt DJ. Increasing prevalence of type 2 diabetes in American Indian children. Diabetologia 1998; 41: 904-10.

4 Harris MI. Summary. In: Harris MI, Cowie CC, Stern MP, Boyko EJ, Reiber GE, Bennett PH, eds. Diabetes in America. 2nd ed. DHHS Publication No. (NIH) 95-1468. Washington, DC: US Department of Health and Human Services, National Institutes of Health, 1995; 1-14.

5 Will JC, Strauss KF, Mendlein JM, Ballew C, White LL, Peter DG. Diabetes mellitus among Navajo Indians: findings from the Navajo Health and Nutrition Survey. Journal of Nutrition 1997; 127: 2106S-13S

6 US Department of Health and Human Services, Indian Health Service, Office of Public Health. Regional Differences in Indian Health, 1998-99 [online]. Available at: http:// www.ihs.gov/publicinfo/publications/trends98/region98. asp. Accessed 12 April 2004

7 Nelson KM, Reiber G, Boyko EJ. Diet and exercise among adults with type 2 diabetes. Findings from the third National Health and Nutrition Examination Survey (NHANES III). Diabetes Care 2002; 25: 1722-8.

8 Miller CK, Jensen GL, Actherberg CL. Evaluation of a food label nutrition intervention for women with type II diabetes mellitus. Journal of the American Dietetic Association 1999; 99: $323-8$.

9 Miller CK, Edwards L, Kissling G, Sanville L. Nutrition education improves metabolic outcomes among older adults with diabetes mellitus: results from a randomized control trial. Preventive Medicine 2002; 34: 252-9.

10 Humphry J, Jameson LM, Beckham S. Overcoming social and cultural barriers to care for patients with diabetes. Western Journal of Medicine 1997; 167: 138-44.

11 Young TK, Mustard CA. Undiagnosed diabetes: does it matter? Canadian Medical Association Journal 2001; 164: $24-8$.

12 Casper M, Rith-Najarian S, Croft J, Giles W, Donehoo R. Blood pressure, diabetes, and body mass index among Chippewa and Menominee Indians: the Inter-Tribal Heart Project preliminary data. Public Health Reports 1996; 111: 37-9.

13 Greenlund KJ, Valdez R, Casper ML, Rith-Najarian S, Croft JB. Prevalence and correlates of the insulin resistance syndrome among Native Americans: the Inter-Tribal Heart Project. Diabetes Care 1999; 22: 441-7.

14 Centers for Disease Control and Prevention (CDC). InterTribal Heart Project: Results from the Cardiovascular Health
Survey. Atlanta, GA: CDC, US Department of Health and Human Services, 1996.

15 Mayfield J, Rith-Najarian S, Acton K, Schraer C, Stahn R, Johnson M, et al. Assessment of diabetes care by medical record review: the Indian Health Service Model. Diabetes Care 1994; 17: 918-23.

16 Friedwald WT, Levy RI, Fredrickson DS. Estimation of the concentration of low density lipoprotein cholesterol in plasma without use of the preparative ultracentrifuge. Clinical Chemistry 1972; 18: 499-501.

17 National Cholesterol Education Program. Detection, Evaluation, and Treatment of High Blood Cholesterol in Adults (Adult Treatment Panel II). NIH Publication No. 93-3095. Bethesda, MD: National Heart, Lung, and Blood Institute, National Institutes of Health, 1993.

18 National Institutes of Health (NIH). The Sixth Report of the Joint National Committee on Prevention, Detection, Evaluation, and Treatment of High Blood Pressure. NIH Publication No. 98-4080. Rockville, MD: National Heart, Lung, and Blood Institute, NIH, 1997.

19 National Heart, Lung, and Blood Institute. Clinical Guidelines on the Identification, Evaluation, and Treatment of Overweight and Obesity in Adults: the Evidence Report. Rockville, MD: National Heart, Lung, and Blood Institute, National Institutes of Health, 1998.

20 American Diabetes Association. National standards for diabetes self-management education programs and American Diabetes Association review criteria. Diabetes Care 1998; 21: S95-8.

21 Grundy SM, Balady GJ, Criqui MH, Fletcher G, Greenland P, Hiratzka LF, et al. Guide to primary prevention of cardiovascular diseases: a statement for health care professionals from the Task Force on Risk Reduction. American Heart Association Science Advisory and Coordinating Committee. Circulation 1997; 95: 2329-31.

22 Smith SC Jr, Blair SN, Criqui MH, Fletcher GF, Fuster V, Gersh $\mathrm{BJ}$, et al. Preventing heart attack and death in patients with coronary disease. Circulation 1995; 92: 2-4.

23 Centers for Disease Control and Prevention. Missed opportunities in preventive counseling for cardiovascular disease - United States, 1995. MMWR Morbidity and Mortality Weekly Reports 1998; 47: 91-5.

24 Kaplan RM, Hartwell SL, Wilson DK, Wallace JP. Effects of diet and exercise interventions on control and quality of life in non-insulin dependent diabetes mellitus. Journal of General Internal Medicine 1987; 2: 220-7.

25 Padgett D, Mumford E, Hymes M, Carter R. Meta-analysis of the effects of educational and psychosocial interventions on management of diabetes mellitus. Journal of Clinical Epidemiology 1988; 41: 1007-30.

26 Basiotis PP, Lino M, Anand R. The Diet Quality of American Indians: Evidence from the Continuing Survey of Food Intakes by Individuals. Insight No. 12. Washington, DC: US Department of Agriculture, Center for Nutrition Policy and Promotion, 1999.

27 Stegmayer P, Lovrein FC, Smith M, Keller T, Gohdes DM. Designing a diabetes nutrition education program for a Native American community. Diabetes Education 1988; 14: 64-6.

28 Harwell TS, Moore K, McDowall JM, Helgerson SD, Gohdes D. Cardiovascular risk factors in Montana American Indians with and without diabetes. American Journal of Preventive Medicine 2003; 24: 265-9.

29 Diabetes Prevention Program Research Group. Reduction in the incidence of type 2 diabetes with lifestyle intervention or metformin. New England Journal of Medicine 2002; 346: 393-403.

30 Tuomilehto J, Lindstrom J, Eriksson JG, Valle TT, Hamalainen $\mathrm{H}$, Ilanne-Parikka $\mathrm{P}$, et al. Prevention of type 2 diabetes mellitus by changes in lifestyle among subjects with 
impaired glucose tolerance. New England Journal of Medicine 2001; 344: 1343-50.

31 Pan XR, Li GW, Hu YH, Wang JX, Yang WY, An ZX, et al. Effects of diet and exercise in preventing NIDDM in people with impaired glucose tolerance. The Da Qing IGT and Diabetes Study. Diabetes Care 1997; 20: 537-44.

32 Archer SL, Greenlund KJ, Rith-Najarian S, Croft J, Casper ML Association of diabetes education with dietary intake and biochemical parameters: the Inter-Tribal Health Project. Journal of the American Dietetic Association 2002; 102: 1132-5.

33 Gittelsohn J, Wolever TMS, Harris SB, Harris-Giraldo R, Hanley AJG, Zinman B. Specific patterns of food consumption and preparation are associated with diabetes and obesity in a Native Canadian community. Journal of Nutrition 1998; 128: 541-7.

34 Lee ET, Howard BV, Savage PJ, Cowan LD, Fabsitz RR, Oopik $\mathrm{AJ}$, et al. Diabetes and impaired glucose tolerance in three American Indian populations aged 45-74 years. The Strong Heart Study. Diabetes Care 1995; 18: 599-610.

35 Miller CK, Edwards L, Kissling G, Sanville L. Nutrition education improves metabolic outcomes among older adults with diabetes mellitus. Results from a randomized controlled trial. Preventive Medicine 2002; 34: 252-9.

36 Wing RR, Goldstein MG, Acton KJ, Birch LL, Jakcic JM, Sallis $\mathrm{FJ} \mathrm{Jr}$, et al. Behavioral science research in diabetes: lifestyle changes related to obesity, eating behavior, and physical activity. Diabetes Care 2001; 24: 117-23.

37 French S, Jeffery R, Story M, Hannan P, Snyder M. A pricing strategy to promote low-fat snack choices through vending machines. American Journal of Public Health 1997; 87: 849-51.

38 Jeffery RW, French SA, Raether C, Baxter JE. An environmental intervention to increase fruit and salad purchases in a cafeteria. Preventive Medicine 1994; 23: 788-92.

39 Subar AF, Kipnis V, Troiano RP, Midthune D, Schoeller DA,
Bingham $\mathrm{S}$, et al. Using intake biomarkers to evaluate the extent of dietary misreporting in a large sample of adults: The OPEN Study. American Journal of Epidemiology 2003; 158: $1-13$.

40 Goris AH, Westerterp-Plantenga MS, Westerterp KR. Undereating and underrecording of habitual food intake in obese men: selective underreporting of fat intake. American Journal of Clinical Nutrition 2000; 71: 130-4.

41 Kant AK. Nature of dietary reporting by adults in the Third National Health and Nutrition Examination Survey, 19881994. Journal of the American College of Nutrition 2002; 4 $315-27$.

42 Westerterp KR, Goris AH. Validity of the assessment of dietary intake: problems of misreporting. Current Opinion in Clinical Nutrition and Metabolic Care 2002; 5: 489-93.

43 Sorensen G, Morris DM, Hunt MK, Hebert JR, Harris DR, Stoddard A, et al. Work-site nutrition intervention and employees' dietary habits: the Treatwell program. American Journal of Public Health 1992; 82: 877-80.

44 Ievers-Landis CE, Burant C, Drotar D, Morgan L, Trapl ES, Kwoh CK. Social support, knowledge, and self-efficacy as correlates of osteoporosis preventive behaviors among preadolescent females. Journal of Pediatric Psychology 2003; 28: 335-45.

45 Lindholm L, Rosen M. What is the 'golden standard' for assessing population based interventions? Problems of dilution bias. Journal of Epidemiology and Community Health 2000; 54: 617-22.

46 Narayan KM, Hoskin M, Kozak D, Kriska AM, Hanson RL, Pettitt DJ, et al. Randomized clinical trial of lifestyle intervention in Pima Indians. A pilot study. Diabetic Medicine 1998; 15: 66-72.

47 US Department of Health and Human Services, Indian Health Service. National Diabetes Program [onlinel. Available at: http://www.ihs.gov/MedicalPrograms/Diabetes/ index.asp. Accessed 12 April 2004. 